Original Paper http://ajol.info/index.php/ijbcs http://indexmedicus.afro.who.int

\title{
Reproduction and larval rearing of the fresh water prawn, Macrobrachium vollenhovenii in Senegal
}

\author{
Farokh NIASS $^{1^{*}}$ and Soumaya FALL ${ }^{2}$ \\ ${ }^{1}$ Université Gaston Berger de Saint-Louis, Sénégal. \\ ${ }^{2}$ Institut Supérieur de Formation Agricole et Rurale, Université Alioune Diop de Bambey, Sénégal. \\ *Corresponding author; E-mail: farokh.niass@ugb.edu.sn; BP 234; Tel.: (+221)77 6586546
}

\section{ACKNOWLEDGMENTS}

We are acknowledging the project «Crevette » and le Centre de Recherche Biomédicale, Espoir pour la Santé (EPLS) for funding this study.

\begin{abstract}
Macrobrachium vollenhovenii is a crustacean decapod distributed on the rivers of African west coast from Senegal to Angola. This species occurred abundantly in Senegal River during the past but the population decreased drastically after erection of a dam. The aim of this study is to master the reproduction and larval rearing of Macrobrachium vollenhovenii in order to restore its population in Senegal River basin and eventually to farm it for direct human consumption. The reproduction experiment was made in 6 tanks of 75 litres each containing males and females in a ratio of 1:4; 5 tanks of 1250 litres each being able to contain up to 3 males and 12 females. Two 75 litres tanks are connected to a biofilter. A control was daily made to monitor the evolution of the individuals. The larval rearing was carried out by maintaining the water temperature at 29 ${ }^{\circ} \mathrm{C}$ and the salinity at $15 \mathrm{ppt}$. Hatching occurred after 13 to 14 days of incubation. There were 15 larval stages before reaching postlarval one. Since the larval rearing is mastered, the next step would be to try to build up a hatchery in order to produce the species in greater quantity.
\end{abstract}

() 2015 International Formulae Group. All rights reserved.

Keywords: Palaemonidae, Prawn, genitor, hatch, larviculture, postlarvae.

\section{INTRODUCTION}

Macrobrachium vollenhovenii, African river prawn is a crustacean decapod of the Family Palemonides, which is distributed on the west coast of Africa, from Senegal to Angola. The natural environment of Macrobrachium vollenhovenii is mainly rivers, but it depends on brackish water of the estuary to reproduce. Females bearing eggs migrate into the estuary to hatch them. The maximum size range is $182-195 \mathrm{~mm}$ (Holthuis, 1980; Marioghae, 1987; Anetekhai and Fagade, 1987). Macrobrachium vollenhovenii sustains a viable artisanal and commercial fishery in many countries of West Africa (Bello-Olusoji, 1997; Marioghae and Ayinla, 1995; Gabche and Hockey, 1995; Anetekhai, 1986; Holthuis, 1980).

Biological, ecological and distribution field studies are available but old (Marioghae, 
1982; Nwosu and Wolfi, 2006; Bello-Olusoji, 1997; Etim and Sankare, 1998; Gabche and Hockey, 1995; Ville, 1971). Scarce experimental studies also exist (Anetekhai and Fagade, 1987; Willfuhr-Nast et al., 1993). Recent studies on this species are very rare. Konan et al. (2010) focused on morphometric differences between males population of different rivers in Ivory Coast. Makombu et al. (2014) studied the larval rearing of this species in Cameroon. No commercial farm of Macrobrachium vollenhovenii yet exists (Makombu et al., 2014) even though it has an interesting potential for aquaculture as its congeneric Macrobrachium rosenbergii.

Macrobrachium vollenhovenii occurs in Senegal River but since the construction of Diama dam it becomes rare because the dam is an obstruction for the completion of its life cycle which includes a blackish water stage. Therefore mastering the culture of Macrobrachium vollenhovenii is necessary to produce a huge amount of post larvae in order to start a repopulating activity. For the double purpose of commercial and repopulating aquaculture it is unavoidable to develop an efficient hatchery technology. As a first stage the objectives of this study were:

- to reproduce adults Macrobrachium vollenhovenii under captivity,

- to raise larvae from hatching to postlarval stage,

- to determine the different larval stages.

\section{MATERIALS AND METHODS}

The experiment was conducted on two sites, the North Branch office of the Aquaculture National Agency (ANA) in Saint-Louis and the Pisciculture Station in Richard-Toll (Figure 1).

\section{Hatchery}

As biological materials we used Macrobrachium vollenhovenii and Artemia cyst. The hatchery system located in the head office of the National Aquaculture Agency (ANA) in Saint-Louis consists of 12 tanks. The tanks number $1,2,7,8,9$ and 10 were blue and had a capacity of 200 litres each one. They were used for the larviculture and were not connected with filter (Figure 2). The tanks No 3 and 4 (100 litres each one) were also used for larviculture and they were connected to a biofilter (Figure 3). The tank No. 0 was used for fresh water storage. The tanks No 5 and 6 (grey) of 75 litres content each one, were used for storage of genitors and were also connected to a biological filter (Figure 4). One cubic meter content vat was used for sea water storage aimed renewing the water of larviculture tanks. Thirty and 20 litres content buckets were used for mixing sea water and fresh water in order to obtain appropriate salinity for larvae tanks. Above each tank, there was a paper in which all important parameters were reported.

During the experiment, the following materials were used: a plastic cone JBL, knifes, buckets, basins, jars, slurping pipe, 100 $\mathrm{ml}$ graduated cylinder, slurping buckets, Pasteur Pipette, gloves, microscopes, electrical resistances, electronic scales, salinometers, thermometers and photometer.

This study has lasted 12 months, from October 2012 to September 2013.

\section{Hatchery management}

Daily work: Daily working procedures in the hatchery were divided into two parts, the morning (between $7 \mathrm{~h}$ and $8 \mathrm{~h}$ ) and evening (between $19 \mathrm{~h}$ and $20 \mathrm{~h}$ ), that's an intervals lasting 12 hours per day. Before starting the work we made a look around the tanks to ensure that everything was going well i.e. no leaking of water, air pump was working well, lightening of larvae tanks was sufficient. This enlightening is important as it enables larvae to feed. Each tank was set with its specified equipment (slurping pipe, $100 \mathrm{ml}$ graduated cylinder, slurping bucket, pipette) to avoid any contaminations. All parameters were monitored twice a day. The volume of water of the tank was checked. At least $20 \%$ of the volume of water was renewed. The temperature was checked and the thermometer 
was put back to the bottom of the tank. The salinity was measured using a handy refractometer. After every use, it was dried before the next use. The ammonium, Nitrite and $\mathrm{pH}$ were checked with the kit of water parameters. Density of larvae (N/L) was calculated by an average of three samples of $100 \mathrm{ml}$ taken in the tank before the slurping. Densities of Artemia before and after feeding were checked by calculation from an average of three samples of $1 \mathrm{ml}$ taken with a Pasteur pipette.

When a gravid female was placed in a tank, the colour of eggs as well the embryonic stage was checked once a day. In order to minimize the stress, the check was carried out by sampling some animals which were observed under a microscope. As food supply we used at the same time alive prey (Artemia) and some shrimp powder for larvae and granules were reserved for the genitors.

\section{Procedure of salting water}

The salting of water began when the colour of eggs changed from orange to brown. It needed approximately one week to the eggs to reach the stage of brown colour. The desired salinity for larvae on the hatching day is about 7 ppt. The salinity was increased by adding some water with 5 ppt in the first 3 days and 8 ppt in the next 3 days. After the hatching of eggs, the salinity was more quickly increased by adding water with 10,15 or 20 ppt. So the water reached $15 \mathrm{ppt}$ approximately 5 days after the hatching.

\section{Daily preparation of the alive prey}

Larvae were fed with the alive food which is twice prepared per day in the hatchery for use in the next day. Larvae of Macrobrachium vollenhovenii were fed mainly with Artemia nauplie also known as brine shrimp. The kind of Artemia we used in the hatchery was Artemia of San Francisco which is smaller than generally used Artemia salina.
We mixed 2 litres of tap water with 60 $\mathrm{g}$ of clean salt, to have $30 \mathrm{ppt}$ of salinity in the tube of preparation. We ensured that broadcasting of the air by air stone in the tube was working well; otherwise, the air stone was cleaned out. Then $10 \mathrm{~g}$ of cysts of Artemia were added. Artemia was harvested 24 hours after the incubation began and supplied as food to larvae as soon as possible after the harvest. The harvest of Artemia was done using a cone JBL. First, the bottom of the cone JBL was closed and then a culture of Artemia was added in the cone. The top of the cone was covered with a dark coverage and then we waited 5 minutes before opening the bottom of the cone slowly to harvest hatched Artemia which was of orange colour. These stages were repeated 3 or 4 times for harvesting 2 litres culture. The cup containing Artemia was tilted during 1 minute and the solution was poured slowly into another cup, to clear off encapsulated brown cysts and nonhatched cysts which were really deposited down in the bottom (Figure 5).

\section{Larval feeding}

Feeding was done twice daily: 08 AM, 08 PM during the first four days with fresh Artemia nauplie at a rate of 5 nauplie / $\mathrm{ml}$. The concentration of Artemia nauplie was determined using a sample taken from the culture. From the 5th day after hatching, we used another diet (powdered shrimp) during the day (08 AM) and Artemia nauplie once during the night (08 PM). During the last days of growth to postlarval stage, the amount of shrimp powder was increased as well the feeding frequency (Table 1). The amount of non-consumed food was carefully recorded each morning in order to adjust the quantity to feed the following day.

\section{Management of genitors}

The fertilization and the control of the gravid females took place in tanks reserved for the genitors. Before the fertilization, a 
female has to develop an ovary that can be seen by transparency of orange colour inside the cephalothorax. When the female was ready to have eggs, she was chosen by a male, which will protect her and then she will moult (Figure 6). One day after the moult, all the females of the tank were inspected to identify those who are gravid. Then, the gravid females were moved in tanks reserved for hatching or if there was no free space they were kept in the same tank but were isolated beside other animals which were there. During the phase where eggs were orange, the females were guarded first in the fresh water during 1 week, until eggs changed colour and became brown, and then they were moved in a tank with 7 ppt water salinity reserved for the hatching.

The transportation of animals and particularly gravid females was carried out with air supply. The genitors were kept in Saint-Louis and in Richard-Toll but all gravid females were brought to Saint-Louis for hatching and larval rearing.

The following works were carried out regularly for all genitors: throwing out the dead shrimp, cleaning tanks when the bottom was dirty, checking out water parameters and number of animals inside tanks, feeding with the dry food and snails thrice per week and disconnecting and cleaning the filter once a month.

\section{Protocol for the reception of new animals}

Everytime a fisherman indicated us of new shrimps; these were transported by means of buckets connected with an aerator.

These shrimps were kept in the ANA office and the following data were recorded: date and collection site (for example $10 / 3 / 2012$, Diama), the sex of the animal, to be confirmed with the presence or absence of appendix masculine (Male, Female, undefined), the weight, the length of the shell, the length and the width of the biggest propodus, the size of the external tooth of the biggest propodus, other specificities (miss the 2nd right leg; presence of orange eggs, etc.)

When receiving a new adult specimen, we carried out all the work described above. In case of male, it was kept isolated in a container and if the sex was undefined, we took pictures and sent them to a specialist in order to help determining the sex. In case of female we checked if it was bearing eggs or not. If the female was carrying eggs, it was kept in one of the tanks reserved for larval rearing. In case of female not carrying eggs, we kept it in one the grey tanks in a ratio of one male: 4 females.

Microsoft Excel was used to record, organize data and to calculate standard deviation.

\section{RESULTS}

The water temperature has been maintained during all experiment at $29 \pm 0.5$ ${ }^{\circ} \mathrm{C}$. The larvae hatched in fresh water but from the first day to the $12^{\text {th }}$ water salinity was raised gradually to reach $15 \pm 0.5 \%$ (Figure 7).

This experiment finished with postlarvae. The postlarvae are defined as the first juvenile stage characterized by significant behavioural (from pelagic to benthic) and morphological changes (the appearance of long flagellum in antennas).

\section{Results during the incubation period of the eggs}

The eggs were orange when they were freshly generated. Then they turned to brown after seven (07) to ten (10) days, at last they became grey four (04) to five (05) days before hatching (Figure 8). The duration of incubation of Macrobrachium vollenhovenii eggs at a temperature of $29 \pm 0.5^{\circ} \mathrm{C}$ was $13-14$ days. Hatching started at night around midnight (11 PM - 01 AM) and lasted 
between 12-24 h. The hatching occurred even in fresh water or in salinity ranging from 1$15 \mathrm{ppt}$. Thus the perfection of the process of hatching seemed in no way being affected by the salinity of the water.

\section{Results during the phase of larval development}

Larval development of Macrobrachium vollenhovenii took between 64-65 days. Some characteristics were observed during the development stages of larvae. During stage 1, reached one or two days (Table 2) after hatching, the eyes were joined firmly to the head (Figure 9) while they were well shaped and were bounded to the head by a peduncle during stage 2 which was reached at age of 35 days. At stage 3, reached at age of 5-9 days, the first uropod was formed and the bud of the second one was observed while at stage 4 which was reached at age of 9-12 days both uropod were entirely shaped. At stage 5, reached at age of 12-18 days, the $2^{\text {nd }}$ uropod reached the base of the tail. During stage 6, reached at age of 18-25 days, the tail became rectangular and the $4^{\text {th }}$ pereiopods were visible as buds. At stage 7, reached at age of 25-32 days, the edge of the $2^{\text {nd }}$ uropod reached the middle part of the spines of the tail while at stage 8 which was at age of 32-35 days the $2^{\text {nd }}$ uropod was three times longer than spines that were next to the tail. During stage 9, reached at age of 35-45 days, the buds of the 5 pleopods were observed. At stage 10 , reached at age of 45-47 days, the bits of the 5 pleopods were clearly visible. At stage 11, reached at age of 47-50 days, the antenna was divided into 11-12 segments. At stage 12, reached at age of 50-56 days, four to six bits on the upper edge of the rostrum and the antenna having 11-12 segments were observed while at stage 13 which was at age of 57-59 days the antenna was composed of 15 segments. At stage 14, reached at age of 60-62 days, on the upper edge of the rostrum, between $1^{\text {st }}$ and $2^{\text {nd }}$ spine, 6 bits existed and the antenna was then divided into 20 segments. At stage 15, reached at age of 63-64 days, there were 6-7 segments observed on the lower edge of the rostrum and 25 segments at the antenna.

Larval development of Macrobrachium vollenhovenii took about 65 days in our experiment. Macrobrachium vollenhovenii requires a long time to move from one stage to another.

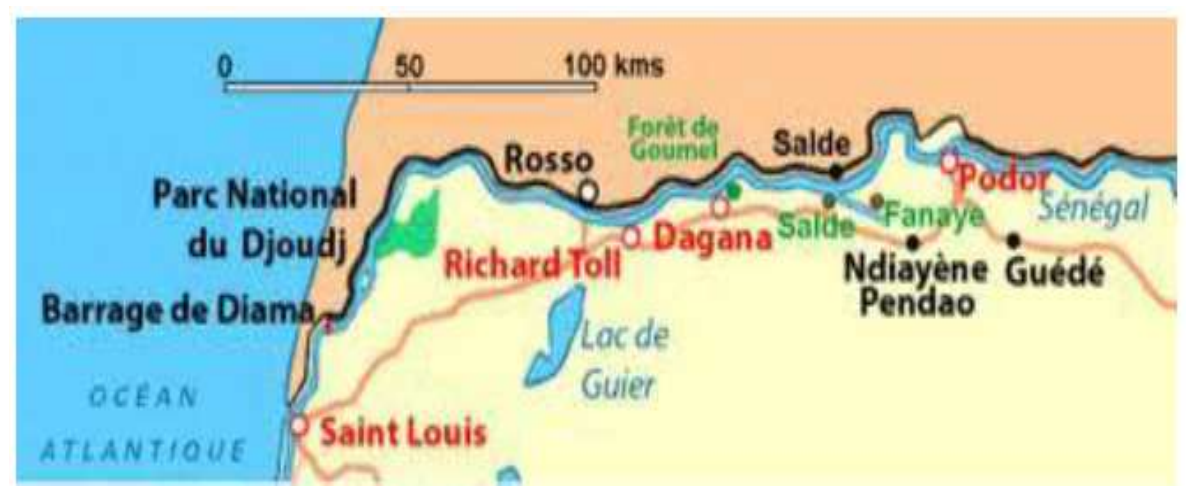

Figure 1: Experimentation field in northern Senegal. 
F. NIASS and S. FALL / Int. J. Biol. Chem. Sci. 9(6): 2523-2534, 2015

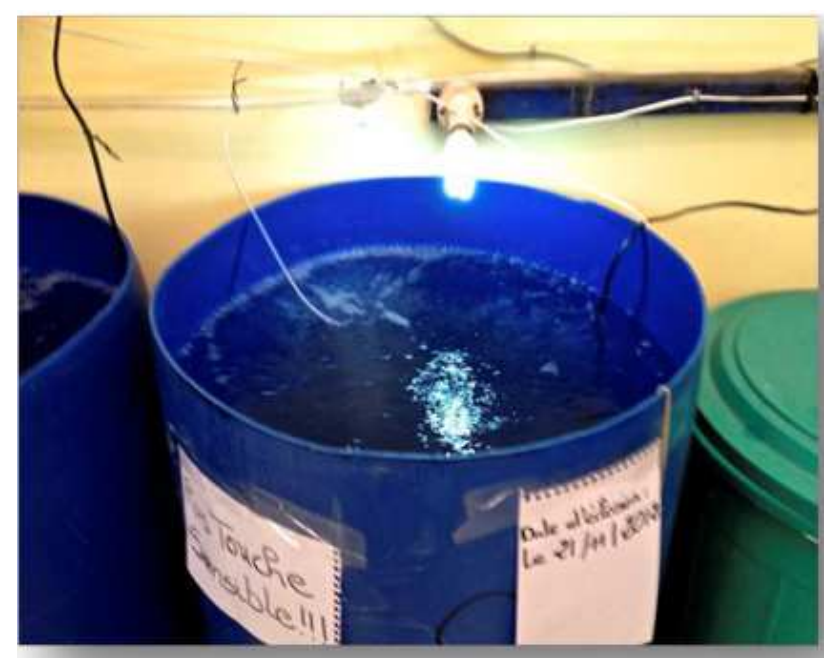

Figure 2: Blue tanks of larvae lighted up by an electric light bulb.

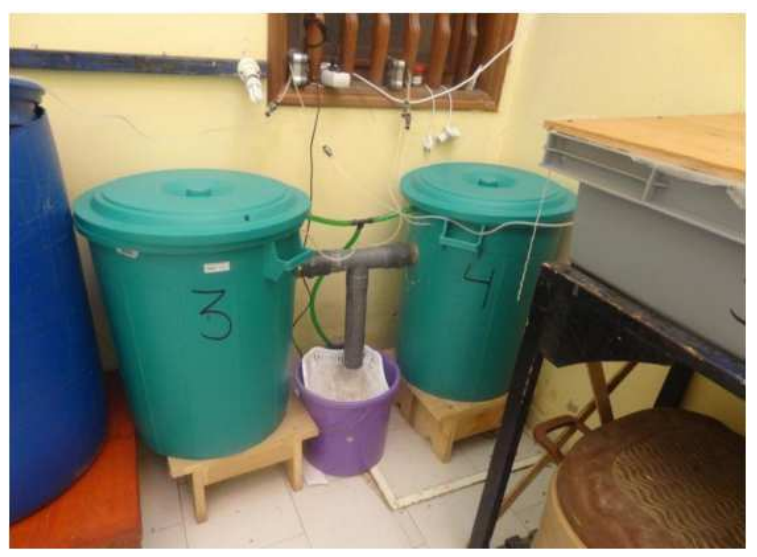

Figure 3: Tanks 3 and 4 of larvae. These two tanks were connected to a biofilter (bucket in the middle).

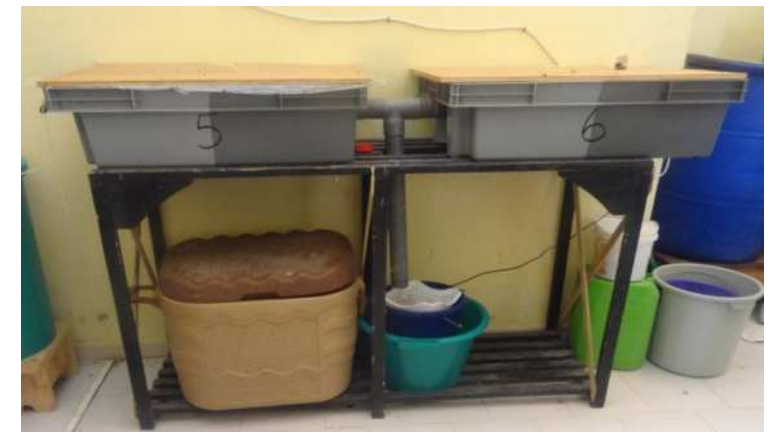

Figure 4: Tanks 5 and 6 of genitors were connected to a biofilter (bucket under desk). 


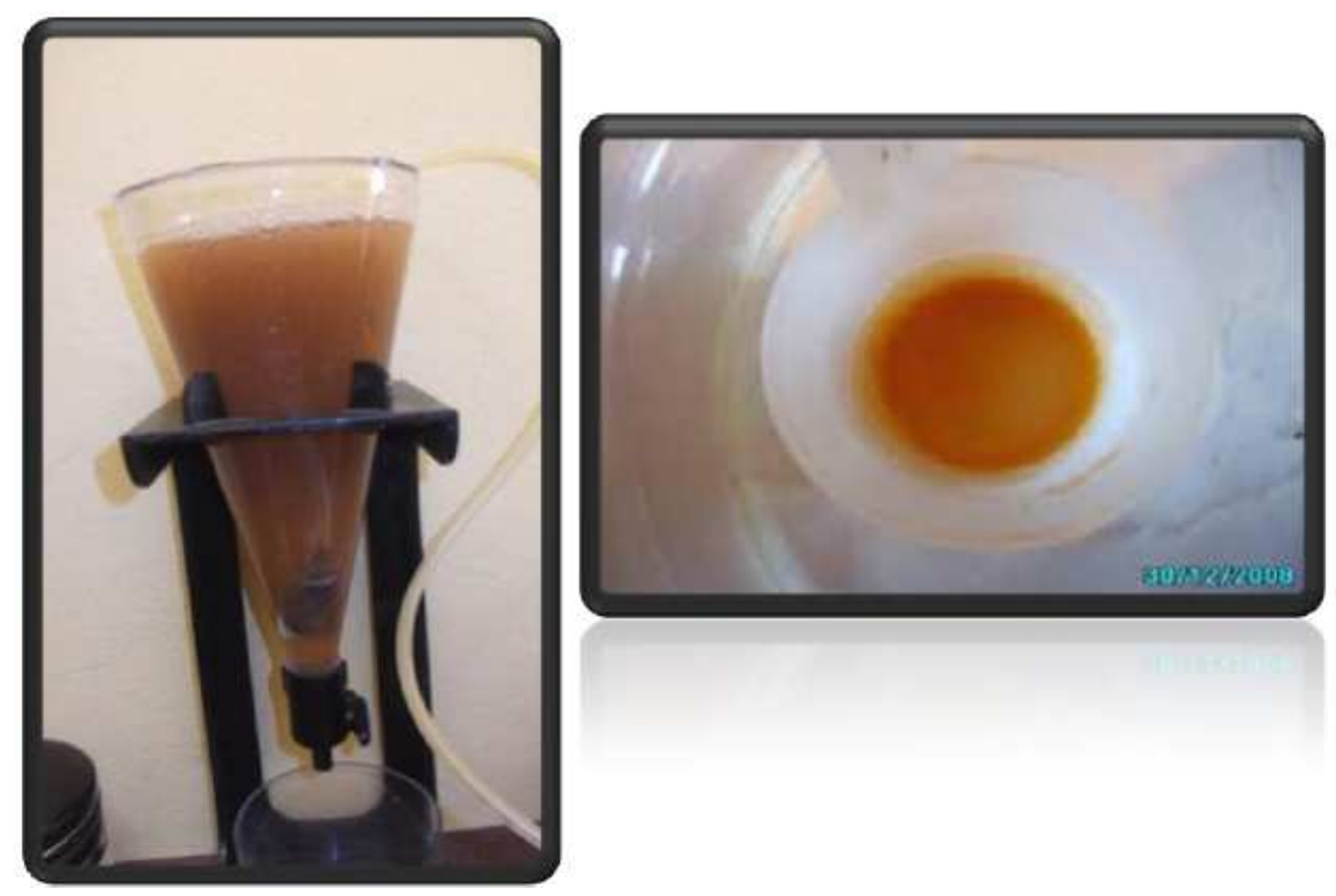

Figure 5: Harvest of Artemia using a cone JBL (picture in the left side) and a cup containing Artemia tilted to clear off encapsulated brown cysts and non-hatched cysts which were really deposited down in the bottom (picture in the right side).

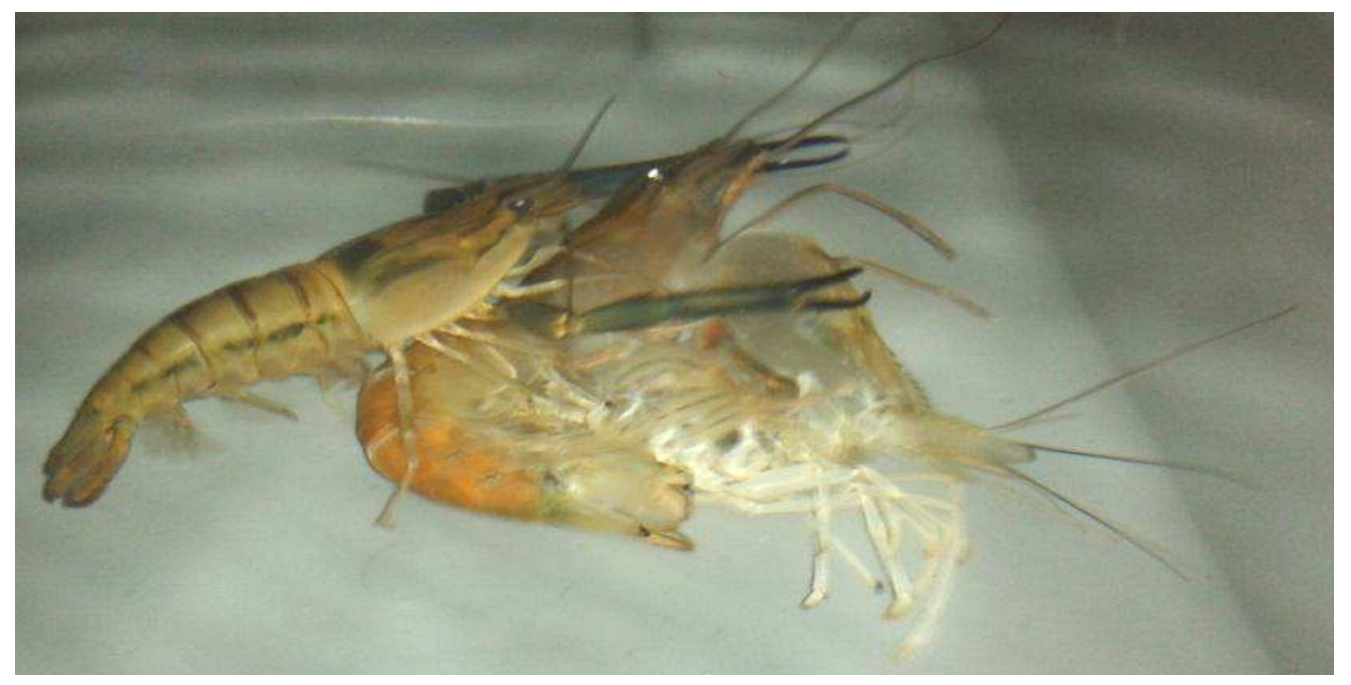

Figure 6: A male protecting a female which has just moulted. 


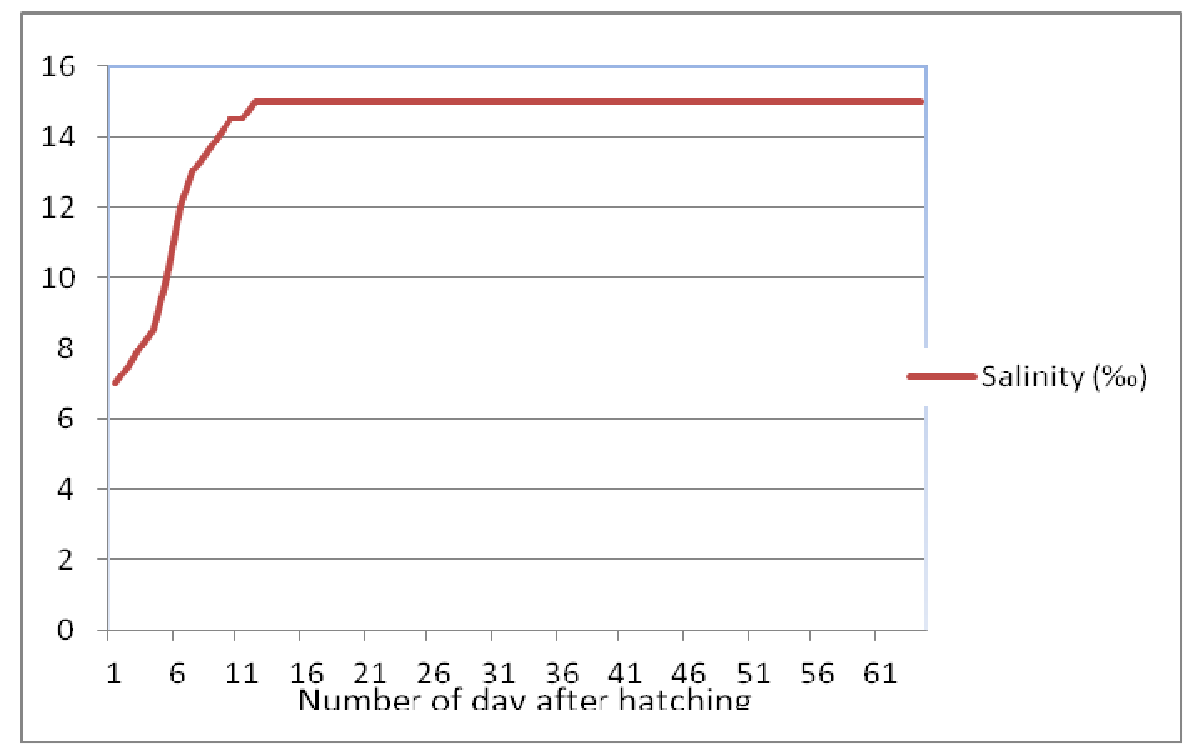

Figure 7: Water salinity (\%o) evolution during larval rearing.

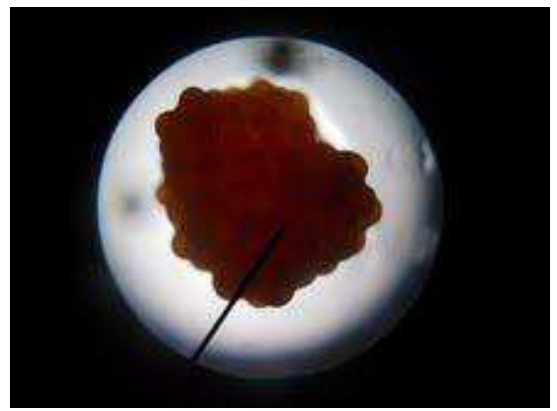

Fresh orange eggs

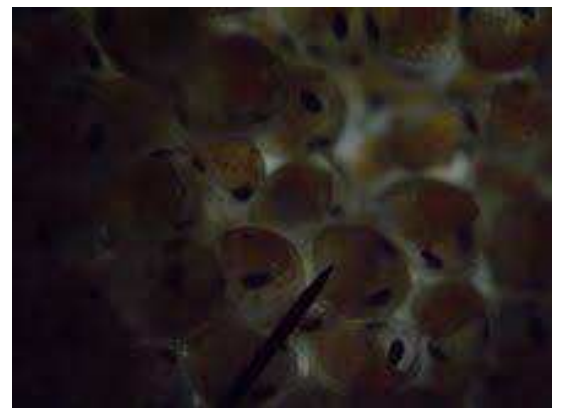

Brownish eggs

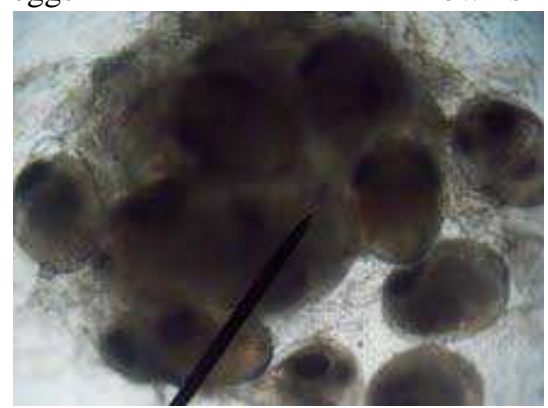

Greyish eggs

Figure 8: Aspects of the eggs at different stages. The eggs were orange when they were freshly generated, then they turned to brown after seven to ten days, at last they became grey four to five days before hatching. 


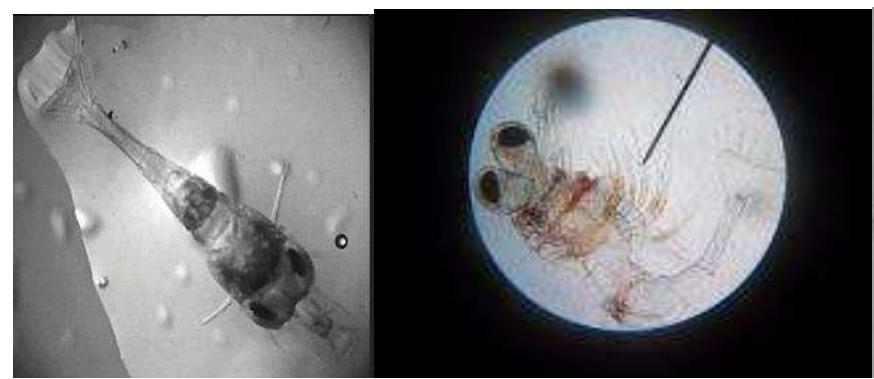

a) Stage 1

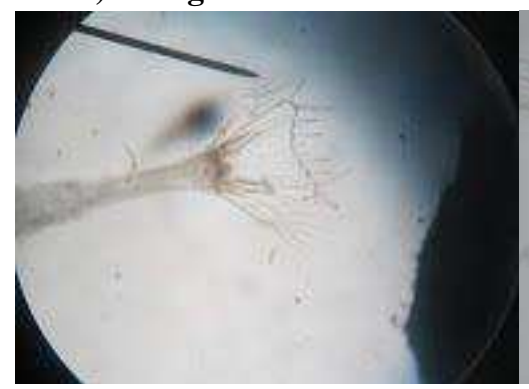

c) Stage 3
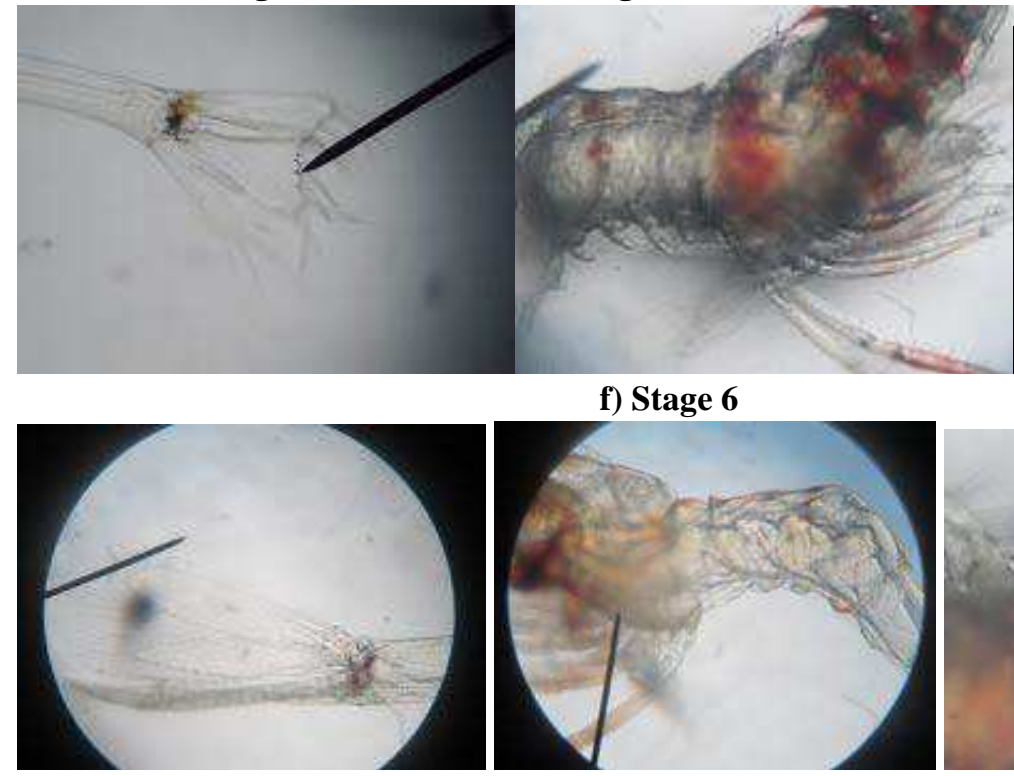

h) Stage 8

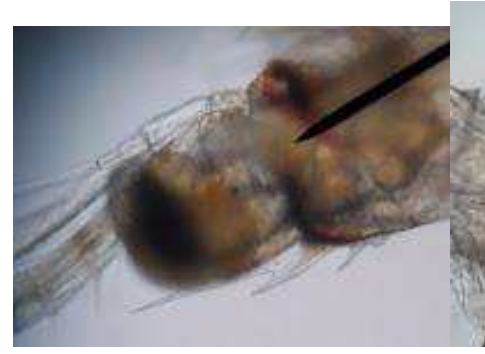

k) Stage 11 f) Stage 6

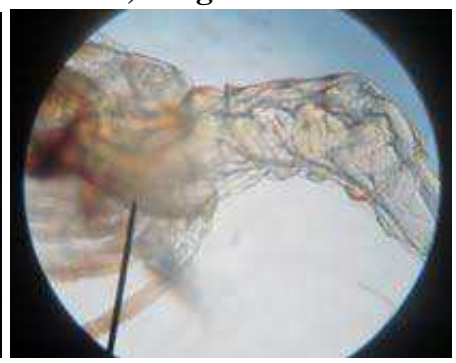

i) Stage 9

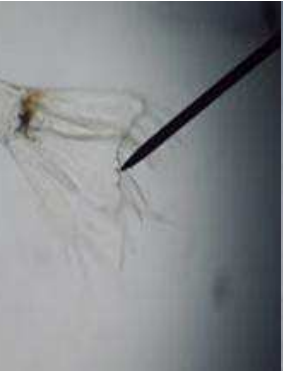

b) Stage 2

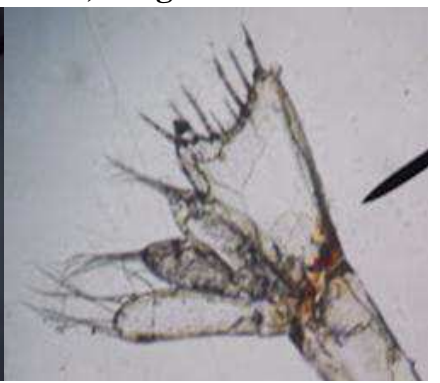

e) Stage 5

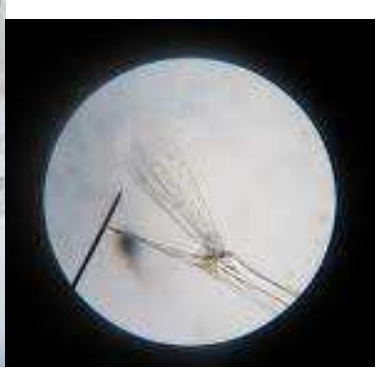

g) Stage 7

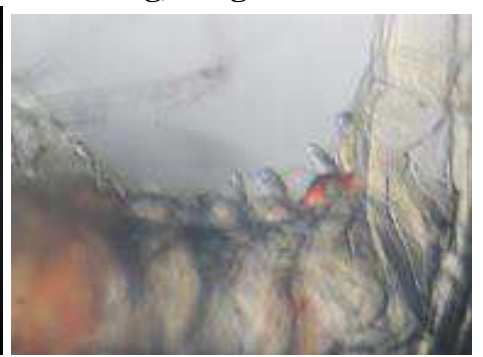

j) Stage 10

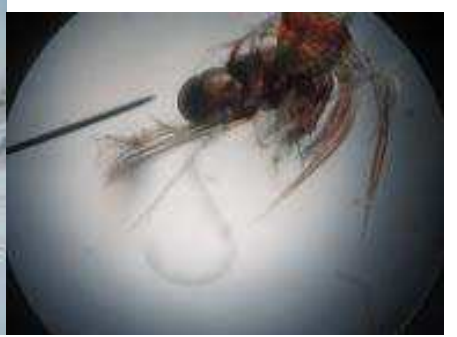

m) Stage 13 


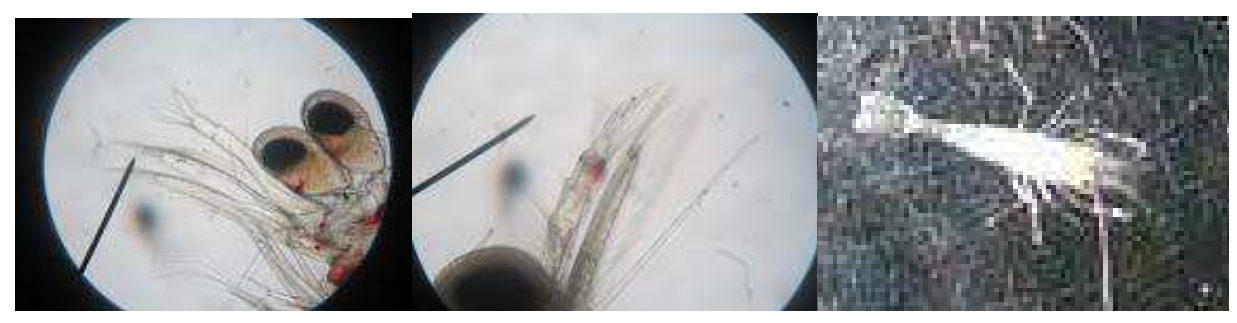

n) Stage 14

o) Stage 15

p) Postlarva

Figure 9: Larval stages and postlarva of Macrobrachium vollenhovenii. a) $1^{\text {st }}$ stage: eyes are firmly joined to the head b) $2^{\text {nd }}$ stage: eyes well shaped and bounded to the head by a peduncle c) $3^{\text {rd }}$ stage: $1^{\text {st }}$ uropod is formed and bud of the $2^{\text {nd }}$ one is visible d) $4^{\text {th }}$ stage: both uropod are entirely shaped e) $5^{\text {th }}$ stage: $2^{\text {nd }}$ uropod grows up and reachs the base of the tail f) $6^{\text {th }}$ stage: the tail gets a rectangular form and the $4^{\text {th }}$ pereiopod buds are visible g) $7^{\text {th }}$ stage: posterior edge of $2^{\text {nd }}$ uropod reachs the middle part of spines of the tail h) $8^{\text {th }}$ stage: $2^{\text {nd }}$ uropod three folds longer than spines next to the tail i) $9^{\text {th }}$ stage: buds of the 5 pleopods are visibles j) $10^{\text {th }}$ stage: 5 pleopods are visibles as bits $\mathrm{k}$ ) $11^{\text {th }}$ stage: antenna is composed of 11-12 segments 1) $12^{\text {th }}$ stage: 4 to 6 bits on the upper edge of rostrum m) $13^{\text {th }}$ stage: antenna is composed of 15 segments $\mathrm{n}$ ) $14^{\text {th }}$ stage: antenna is composed of 20 segments o) $15^{\text {th }}$ stage: antenna is composed of 25 segments and 6-7 segments are visibles on lower edge of rostrum p) postlarva: all morphological caracters of the adult prawn are visibles.

Table 1: Feeding according to larval stage from 2 litres of a preparation of Artemia containing 5000 nauplius.

\begin{tabular}{lcc}
\hline $\begin{array}{l}\text { Larval stages of } \\
\text { M. vollenhovenii }\end{array}$ & Quantity of Artemia $(\mathbf{m l})$ & Shrimp powder amount (g) \\
\hline I - II & 5 & - \\
III - V & 5 & $0.70-1.0$ \\
VI - VII & 5 & $3.00-5.0$ \\
IX - X & 10 & $6.00-8.0$ \\
X - Postlarvae & 10 & $12.00-14.0$ \\
\hline
\end{tabular}

Table 2: Ages of various larval stages of Macrobrachium vollenhovenii.

\begin{tabular}{cc}
\hline Age of larvae (day) & Larval development stages \\
\hline $1-2$ & Stage 1 \\
$3-5$ & Stage 2 \\
$5-9$ & Stage 3 \\
$9-12$ & Stage 4 \\
$12-18$ & Stage 5 \\
$18-25$ & Stage 6 \\
$25-32$ & Stage 7 \\
$32-35$ & Stage 8 \\
$35-45$ & Stage 9 \\
$45-47$ & Stage 10 \\
$47-50$ & Stage 11 \\
$50-56$ & Stage 12 \\
$57-59$ & Stage 13 \\
$60-62$ & Stage 14 \\
$63-64$ & Stage 15 \\
$64-65$ & Postlarva \\
\hline
\end{tabular}




\section{DISCUSSION}

Overall, this study permitted to determine the optimal settings for the hatchery and larval rearing of Macrobrachium vollenhovenii and to keep the life genitors in the tanks.

Recently, Makombou et al. (2014) studied larval development of the species in Cameroon and found only 11 distinct larval stages like in $M$. rosenbergii while in our experiment, we got 15 stages before reaching postlarvae. This difference is certainly due to the fact that we count that after every moulting we have a new larval stage.

Ville (1971) observed that the first moult takes about 05-08 days after hatching.

Anetekhai and Fagade (1988) argued that the first moult takes place 06-07 days after hatching. In our experiment, this takes place one or two days after hatching.

Ultimately, it is possible to reproduce Macrobrachium vollenhovenii in an artificial environment. To do this, compliance with a range of temperatures between $28-30{ }^{\circ} \mathrm{C}$ is required with a salinity reached $5 \mathrm{ppt}$ day of hatching. This salinity is increased gradually to 15 ppt after two weeks.

Ville (1971) also reported that larval development of Macrobrachium vollenhovenii lasted between 30-45 days while in our experiment, it lasted between $64-65$ jours. This difference is due to the fact that in our case, the rearing temperature was certainly lower. Specifically, this study has permitted to:

- Build, maintain and improve reproductive systems;

- Ensure proper animal health and water quality (direct observations, measurements of parameters, water renewal, etc.);

- Identify and monitor the various stages of reproduction (presence of ovaries, eggs, larvae, etc.) to immediately adjust the conditions and salinity;

- Determine the existence of a social structure and follow the stages of evolution of male (morphological differentiation, dominance).
Since the larval rearing is mastered, the next step would be to try to build up a hatchery in order to produce a huge amount of postlarvae of this species.

\section{COMPETING INTEREST}

The authors declare that there is no competing interest for this article.

\section{AUTHORS' CONTRIBUTIONS}

$\mathrm{SF}$ and AS assisted the main author to carry out this research; FN supervised the work and wrote the manuscript.

\section{REFERENCES}

Anetekhai MA. 1986. Aspects of the bioecology of the African river prawn Macrobrachium vollenhovenii (Herklots) in Asejire Lake, Oyo State Nigeria. $\mathrm{PhD}$ thesis, University of Ibadan, Ibadan, Nigeria.

Anetekhai MA, Fagade SO. 1987. Induced spawning and laboratory rearing of the larvae of the African river prawn Macrobrachium vollenhovenii (Herklots) caught at Asejire Lake. Paper presented to the National Fisheries Development Committee meeting, 27-30 April, 1987, Port Harcourt, Nigeria.

Bello-Olusoji OA. 1997. Assessment of the African River Prawn Macrobrachium vollenhovenii (Herklots, 1857) in some lentic and lotic environments in Nigeria. African Journal of Ecology, 35(1): 80-87.

Etim L, Sankare Y. 1998. Growth and mortality, recruitment and yield of freshwater shrimp, Macrobrachium vollenhovenii Herklots, 1857 (Crustacea, Palaemonidae) in the Faye reservoir, Côte d'Ivoire, West Africa. Fisheries Research, 38: 211-223.

Gabche CE, Hockey HUP. 1995. Growth and mortality of the giant Africa River prawn, Macrobrachium vollenhovenii (Herklots: Crustecea, Palaemonidae) in the Lobe River, Cameroon: A 
preliminary evaluation. Journal of Shellfish Research, 14(1): 185-190.

Holthuis LB. 1980. Shrimps and prawns of the world: An annotated catalogue of species of interest to fisheries. FAO Fisheries Synopsis $\mathrm{N}^{\circ}$ 125, Vol 1, FAO: Rome.

Konan KM, Adépo-Gourène AB, Ouattara A, Nyingy WD, Gourène G. 2010. Morphometric variation among male populations of freshwater shrimp Macrobrachium vollenhovenii Herklots, 1851 from Cote d'Ivoire Rivers Fisheries Research, 103: 1-8.

Makombu JG, Oben PM, Oben BO, Gaudin GLP, Motto IS, Makoge N, Syapze JK, Brown JH, Ngueguim JR, Mialhe E. 2014. Complete Larval Development of the Fresh Water Prawn Macrobrachium vollenhovenii in Cameroon. Journal of Applied Aquaculture, 26: 310-328.

Marioghae IE. 1982. Notes on the biology and distribution of Macrobrachium vollenhovenii and Macrobrachium macrobrachion in the Lagos lagoon (Crustacea, Decapoda, Palamonidae). Revue de Zoologie Africaine, 94(3): 493-508.

Marioghae IE. 1987. An appraisal of the cultivability of Nigerian Palaemonid prawns. Working paper ARAC/87/WP/4. Port Harcourt, Nigeria: African Regional Aquaculture Centre (ARAC).
Marioghae IE, Ayinla OA. 1995. The reproductive biology and culture of Macrobrachiumvollenhovenii (Herklots, 1857) and Macrobrachium macrobrachion (Herklots, 1851) in Nigeria. Technical paper 100. African Regional Aquaculture Centre, Nigerian Institute for Oceanography and Marine Research, Port Harcourt, Nigeria, 16 pp.

Nwosu FM, Wolfi M. 2006. Population dynamics of the giant African River prawn Macrobrachium volllenhovenii Herklots $1857 \quad$ (Crustacea, Palaemonidae) in the Cross River Estuary, Nigeria. West Africa Journal of Applied Ecology, 9: 14.

Ville JP. 1971. Reproductive biology of Macrobrachium of Ivory Coast III. Description of the first stages of Macrobrachium vollenhovenii (Herklots, 1857). Annales de l'Université d'Abidjan, série. E, (Ecologie) 4(1): 325-341.

Willführ-Nast J, Rosenthal H, Udo PJ, Nast F. 1993. Laboratory cultivation and experimental studies of salinity effects on larval development in the African river prawn Macrobrachium vollenhovenii (Decapoda, Palaemonidae). Aquatic Living Resources, 6: 115-137. 